after real-life data suggests that 'unplanned' quit attempts are more successful than 'planned' ones. Hence the "catastrophe theory," where smokers have varying levels of motivational "tension" to stop, and then "triggers" in the environment result in a sudden switch in motivational state; if that switch involves immediate renunciation of cigarettes, this can signal a more complete transformation. ${ }^{11}$ Tailoring a visual tool to trigger a "catastrophic switch" may yield more benefits. Other visual tools could be developed for those who can't or won't immediately quit, which may be just as effective as abrupt quit dates. $^{12}$

This pilot ${ }^{7}$ should be likened to a Phase 1 trial. Almost anything needing new skills and precious consultation time will encounter some resistance. This did not happen here, with a similar duration of counselling sessions and similar GPs' ratings on practicability and usefulness. This is the crux of the study. The additional tool was well used. Like any good research, it opens up more questions and opportunities. It has passed Phase 1, so now is the time for Phase 2 and onwards. Their tool could be tried instead of the IPCRG tool. They could develop aids based on other prevalent illnesses, or aids for less motivated or difficult-to-reach smokers (those with mental illness, pregnant smokers, manual workers and ethnic minorities) where smoking rates and health inequalities continue to grow. NeunerJehle's team needs to continue this work. As former Australian Health Minister Nicola Roxon has said, "We are killing people by not acting." 13

Conflicts of interest The author declares that he has no conflicts of interest in relation to this article.

Commissioned article; not externally peer-reviewed; accepted 21st October 2013; online 28th November 2013

(c) 2013 Primary Care Respiratory Society UK. All rights reserved

http://dx.doi.org/10.4104/pcri.2013.00098

Prim Care Respir J 2013; 22(4): 387-388

\section{References}

1. Doll R, Peto R, Boreham J, Sutherland I. Mortality in relation to smoking: 50 years' observations on male British doctors. BMJ 2004;328(7455):1519. http://dx.doi.org/10.1136/ bmj.38142.554479.AE

2. Schroeder SA. New evidence that cigarette smoking remains the most important health hazard. N Engl J Med 2013;368(4):389-90.

http://dx.doi.org/10.1056/NEJMe1213751

3. Fiore MC and Baker TB. Clinical practice. Treating smokers in the health care setting. N Engl J Med 2011;365(13):1222-31.

http://dx.doi.org/10.1056/NEJMcp1101512

4. Rigotti NA. Strategies to help a smoker who is struggling to quit. JAMA 2012; 308(15):1573-80. http://dx.doi.org/10.1001/jama.2012.13043

5. Stead LF, Buitrago D, Preciado N, Sanchez G, Hartmann-Boyce J, Lancaster TI. Physician advice for smoking cessation. Cochrane Database Syst Rev, 2013;5: p. CD000165.

6. Fiore MC, Jaén CR, Baker TB. Treating Tobacco Use and Dependence: 2008 Update. 2008, US Department of Health and Human Services. Public Health Service.

7. Neuner-Jehle S, Knecht Ml, Stey-Steurer C, Senn O. Acceptance and practicability of a visual communication tool in smoking cessation counselling: a randomised controlled trial. Prim Care Respir J 2013;22(4):412-16.

http://dx.doi.org/10.4104/pcrj.2013.00086

8. Statistics on Smoking:England, 2013. 2013 [cited 201314 October]; Available from: https://catalogue.ic.nhs.uk/publications/public-health/smoking/smok-eng2013/smok-eng-2013-rep.pdf.

9. Docherty G, McNeill A, Gartner C, Szatkowski L. Did hardening occur among smokers in England from 2000 to 2010? Addiction 2013; http://dx.doi.org/10.1111/add.12359 [Epub ahead of print]

10. Nohlert E, Helgason AR, Tillgren P, Tegelberg A, Johansson P. Comparison of the cost-effectiveness of a high- and a low-intensity smoking cessation intervention in Sweden: a randomized trial. Nicotine Tob Res 2013;15(9):1519-27. http://dx.doi.org/10.1093/ntr/ntt009

11. West $R$ and Sohal T. "Catastrophic" pathways to smoking cessation: findings from national survey. BMJ 2006;332(7539):458-60. http://dx.doi.org/10.1136/bmj.38723.573866.AE

12. Lindson-Hawley, N., P. Aveyard, and J.R. Hughes, Reduction versus abrupt cessation in smokers who want to quit. Cochrane Database Syst Rev 2012;11: p. CD008033.

13. Launch of the Preventative Health Strategy: task force report, 2009, Australian Government Department of Health and Ageing.

\title{
Poor reporting may infer poor science: lessons learned from asthma trials
}

\section{*Jasper V Been'1, Daniel Kotz', Onno CP van Schayck'}

1 School for Public Health and Primary Care (CAPHRI), Maastricht University Medical Centre, Maastricht, Netherlands

*Correspondence: Dr. Jasper V. Been, Department of Paediatrics, School for Public Health and Primary Care (CAPHRI), Maastricht University Medical Centre, PO Box 5800, 6202 AZ Maastricht, Netherlands

Tel: 0031-43-387 6543 Fax: 0031-43-387 5246

E-mail: jasper.been@mumc.nl
See linked article by Ntala et al. on pg 417

High-quality studies are generally considered the best directors of medical decision-making and policy development. Although the randomised controlled trial (RCT) is the gold standard for intervention research, flaws in methodology and trial processes can severely affect the validity of its findings. Assessment of trial validity can be further hampered by poor reporting of its design and findings. The Consolidated Standards of Reporting Trials (CONSORT) Statement was developed and subsequently updated in an attempt to increase insight into the validity of RCTs by providing guidelines for their reporting. ${ }^{1}$ CONSORT provides a checklist of key items that 
Table 1. Comparison of CONSORT reporting quality in recent systematic reviews

\begin{tabular}{|c|c|c|c|c|c|c|c|}
\hline Author, year & $\begin{array}{l}\text { Ntala } \\
2013^{3}\end{array}$ & \multicolumn{2}{|l|}{$\begin{array}{l}\text { Turner } \\
2012^{5}\end{array}$} & $\begin{array}{l}\text { Reveiz } \\
2010^{4}\end{array}$ & $\begin{array}{l}\text { Sinha } \\
2009^{7}\end{array}$ & $\begin{array}{l}\text { Strech } \\
2011^{6}\end{array}$ & $\begin{array}{l}\text { Zavitsanos } \\
2013^{8}\end{array}$ \\
\hline Number of trials & 35 & \multicolumn{2}{|c|}{$\begin{array}{l}\text { 497-2396 depending on } \\
\text { CONSORT item }\end{array}$} & 148 & 42 & 105 & 65 \\
\hline Topic & Asthma & $\begin{array}{l}\text { CONSORT } \\
\text { endorsing } \\
\text { journals }\end{array}$ & $\begin{array}{l}\text { Non-CONSORT } \\
\text { endorsing } \\
\text { journals }\end{array}$ & $\begin{array}{l}\text { High impact } \\
\text { general } \\
\text { medical journals }\end{array}$ & $\begin{array}{l}\text { Surgical } \\
\text { trials }\end{array}$ & $\begin{array}{l}\text { Bipolar } \\
\text { disorders }\end{array}$ & Uro-lithiasis \\
\hline Participants & $34-51$ & 43 & 67 & 88 & NR & $57-90$ & NR \\
\hline Interventions & 66 & 94 & 96 & 85 & NR & $90-98$ & NR \\
\hline Outcomes & 71 & 70 & 65 & 80 & NR & $71-90$ & NR \\
\hline Sample size & 60 & 61 & 35 & 87 & 64 & 35 & $\mathrm{NR}$ \\
\hline Randomisation & & & & & & & NR \\
\hline Blinding & 57 & 64 & 52 & 25 & $5-19$ & $41-94$ & 3 \\
\hline Statistics & $83-91$ & 81 & 82 & 92 & NR & $55-97$ & NR \\
\hline
\end{tabular}

Comparison of percentage of studies reporting selected CONSORT items (Methods section only) between the study by Ntala et al and a recent systematic review plus four other case studies of trial reporting quality. Ranges are given when items were split into sub-items in corresponding reports. NR = not reported.

should be reported when publishing trial results, such as patient eligibility, randomisation procedure, and blinding. ${ }^{2}$

In this issue of the $P C R J$, Ntala and colleagues report their findings of a systematic review of reporting quality of RCTs conducted in patients with asthma. ${ }^{3}$ The percentage of adequately reported CONSORT items varied between 39 and $91 \%$ among the 35 included studies. Less than half of the studies adequately reported over $60 \%$ of the items. Since the authors only included studies from high impact journals, overall reporting quality of asthma trials is likely to be lower. ${ }^{4}$ Given that the authors further restricted their search to one medical database, to a 1.5 year period, and to asthma trials published in journals from two subject fields, the findings should be interpreted as a case-study and therefore generalisability is limited.

Therefore, several questions remain. Is this reporting problem specific to asthma studies? Is the problem specific to respiratory journals? And has there been any progress in reporting quality over time?

The largest and most recent systematic review on this topic showed evidence of some improvement in reporting from studies assessed using the 1996 CONSORT statement to those assessed using the 2001 version. ${ }^{5}$ Completeness of reporting between this previous review and the current paper by Ntala and colleagues is roughly comparable, although considerable variation exists across individual items (see Table 1). 3,5 Whereas this may seem to suggest that no further improvement in reporting occurred, an updated systematic review of the contemporaneous evidence base is required to assess overall progress in reporting quality. Comparison with recent systematic reviews of trial reporting quality in other subject fields identified via an explorative electronic literature search quickly reveals that the problem is not confined to asthma studies or respiratory journals (Table 1) ${ }^{4,6-8}$ Although this demonstrates that we are in good company, the extent of the matter is worrying.

Ntala et al. ${ }^{3}$, as well as others, provide some guidance on how to advance from here, and how to tackle this at different levels. There is evidence that endorsement of CONSORT by medical journals improves the reporting of at least a number of checklist items (Table 1). ${ }^{5}$ This suggests that there is a clear role for medical journal editors, not only in endorsing but also enforcing compliance of submitted manuscripts with the CONSORT checklist. ${ }^{9}$ Authors should be requested to complete a checklist during the submission process, which should be checked by editors and reviewers. Furthermore, there is a particular need for greater adoption of CONSORT in low and middle income countries, as demonstrated by its limited endorsement by medical journals from those countries ${ }^{10,11}$ and the association between location of the corresponding author in a low or middle income country and lower reporting quality in the current study. ${ }^{3}$

However, we believe that the main responsibility lies with the authors of RCT reports. They should recognise that readers and reviewers will often consider reporting quality as a surrogate for methodological study quality: poor reporting thus infers poor science. ${ }^{12,13}$ Although evidence suggests that this is likely to be a misjudgement, ${ }^{14,15}$ it can easily be prevented by better reporting. ${ }^{12}$ When preparing a manuscript, authors should therefore make every effort to comply with the reporting guidelines that are available for their particular study design. ${ }^{16}$ Given the reasonable chance for any research study to be included in a systematic review, authors should also familiarise themselves with commonly used quality appraisal tools, such as the Cochrane risk of bias tool applied here by Ntala and 
colleagues. $^{3}$ Better reporting according to such checklists can contribute to higher quality ranking of a study. ${ }^{12,13}$ It will also serve more accurate appraisal of the available body of evidence on a subject, benefitting subsequent clinical guideline development and policy making.

Whereas historically journal space constraints may have restricted the completeness of reporting, Ntala and colleagues argue that many details can now be reported easily in an online supplement. ${ }^{3}$ Publication and adequate referral to a full trial protocol, as done by only $17 \%$ of studies included in their review, can supply additional essential information. ${ }^{3}$ Ideally, full protocol access should be provided at the time of entry into a trial registry, which can nowadays be considered a prerequisite for eventual publication. ${ }^{4}$ Awaiting further improvement in reporting quality, authors of systematic reviews should consider contacting authors of included studies in an effort to prevent undue interpretation of unreported items as methodological shortcomings. ${ }^{13}$

In conclusion, there is considerable room for improvement in trial reporting quality. Journals should endorse reporting guidelines including CONSORT and specify how compliance is to be enforced. On this specific point, for example, the $P C R J$ can improve the detail in its 'Guide for authors' regarding how inadequate reporting is to be handled. ${ }^{17}$ Authors should ensure compliance of their manuscript with relevant guidelines, and editors and reviewers need to involve the corresponding checklists in their assessment of submitted work. The scientific community has a common responsibility to enable judgment of the clinical applicability of trials to be based on their actual merits rather than reporting adequacy.

Conflicts of interest The authors currently collaborate on several projects with Prof. Aziz Sheikh, the last-named author of the Ntala et al. paper. JB is an Associate editor of, and OCPvS is an Assistant editor of the PCRJ: neither were involved in the editorial review of, nor the decision to publish, this article.

Funding Jasper Been is supported by fellowships from the Netherlands Asthma Foundation, Thrasher Research Fund, the International Pediatric Research Foundation, and the Maastricht University Medical Centre.

Commissioned article; not externally peer-reviewed; accepted 12th November 2013; online 23rd November 2013

(c) 2013 Primary Care Respiratory Society UK. All rights reserved

http://dx.doi.org/10.4104/pcrj.2013.00095

Prim Care Respir J 2013: 22(4): 388-390

\section{References}

1. Schulz KF, Altman DG, Moher D. CONSORT 2010 statement: updated guidelines for reporting parallel group randomised trials. PLOS Med 2010;7(3):e1000251. http://dx.doi.org/10.1371/journal.pmed.1000251

2. http://www. consort-statement.org/consort-statement/overview0/\#checklist [accessed 8 Nov 2013]
3. Ntala C, Birmpili P, Worth A, Anderson NH, Sheikh A. The quality of reporting of randomised controlled trials in asthma: a systematic review. Prim Care Respir $J$ 2013;22(4):417-24. http://dx.doi.org/10.4104/pcrj.2013.00003

4. Reveiz L, Cortes-Jofre M, Asenjo Lobos C, et al. Influence of trial registration on reporting quality of randomized trials: study from highest ranked journals. J Clin Epidemio/ 2010;63(11):1216-22. http://dx.doi.org/10.1016/j.jclinepi.2010.01.013

5. Turner L, Shamseer L, Altman DG, et al. Consolidated standards of reporting trials (CONSORT) and the completeness of reporting of randomised controlled trials (RCTs) published in medical journals. Cochrane Database Syst Rev 2012; 11:MR000030. http://dx.doi.org/10.1002/14651858.MR000030.pub2

6. Strech D, Soltmann B, Weikert B, Bauer M, Pfennig A. Quality of reporting of randomized controlled trials of pharmacologic treatment of bipolar disorders: a systematic review. J Clin Psychiatry 2011;72(9):1214-21. http://dx.doi.org/10.4088/JCP.10r06166yel

7. Sinha S, Ashby E, Jayaram R, Grocott MP. Quality of reporting in randomized trials published in high-quality surgical journals. J Am Coll Surg 2009;209(5):565-71 e1. http://dx.doi.org/10.1016/j.jamcollsurg.2009.07.019

8. Zavitsanos PJ, Bird VG, Mince KA, Neuberger MM, Dahm P. Low Methodological and Reporting Quality of Randomized Controlled Trials for Devices to Treat Urolithiasis. J Urol 2013; published online 21 October 2013. http://dx.doi.org/10.1016/j.juro.2013.10.067.

9. Hopewell S, Altman DG, Moher D, Schulz KF. Endorsement of the CONSORT Statement by high impact factor medical journals: a survey of journal editors and journal 'Instructions to Authors'. Trials 2008;9:20.

http://dx.doi.org/10.1186/1745-6215-9-20

10. Li XQ, Tao KM, Zhou QH, et al. Endorsement of the CONSORT statement by highimpact medical journals in China: a survey of instructions for authors and published papers. PLoS One 2012;7(2):e30683. http://dx.doi.org/10.1371/journal.pone.0030683

11. Tharyan P, Premkumar TS, Mathew V, Barnabas JP, Manuelraj. Editorial policy and the reporting of randomized controlled trials: a survey of instructions for authors and assessment of trial reports in Indian medical journals (2004-05). Natl Med J India 2008;21(2):62-8.

12. Juni $P$, Altman DG, Egger M. Systematic reviews in health care: Assessing the quality of controlled clinical trials. BMJ 2001;323(7303):42-6.

http://dx.doi.org/10.1136/bmj.323.7303.42

13. Littlewood C, Ashton J, Chance-Larsen K, May S, Sturrock B. The quality of reporting might not reflect the quality of the study: implications for undertaking and appraising a systematic review. J Man Manip Ther 2012;20(3):130-4. http://dx.doi.org/10.1179/2042618611Y.0000000013

14. Devereaux PJ, Choi PT, El-Dika S, et al. An observational study found that authors of randomized controlled trials frequently use concealment of randomization and blinding, despite the failure to report these methods. I Clin Epidemiol 2004;57(12):1232-6. http://dx.doi.org/10.1016/j.jclinepi.2004.03.017

15. Soares HP, Daniels S, Kumar A, et al. Bad reporting does not mean bad methods for randomised trials: observational study of randomised controlled trials performed by the Radiation Therapy Oncology Group. BMJ 2004;328(7430):22-4. http://dx.doi.org/10.1136/bmj.328.7430.22

16. http://www.equator-network.org [accessed 30 Oct 2013]

17. http://www.thepcrj.org/authors/pcrj_guide_for_authors.pdf [accessed 8 Nov 2013] 